Computers in Human Behavior, Vol. xx. No. xxx, pp. xxx-xxx.

\author{
Sanna Sintonen*a \& Mika Immonen ${ }^{b}$ \\ ${ }^{a}$ School of Business, Lappeenranta University of Technology \\ ${ }^{b}$ Faculty of Technology Management, Lappeenranta University of Technology \\ * corresponding author
}

\title{
Telecare services for aging people: Assessment of critical factors influencing adoption intention
}

\begin{abstract}
Dimensions of telecare services are analyzed and contrasted those to theories of behavioural intention. Factors influencing innovation adoption are derived from target group specific factors and telecare features as well. We provide results of an empirical study which interlinks users' characteristics, technology and intention to adopt technology based services. We examine customers above 55 years regarding their physical, psychological and cognitive limitations. The central objective is to assess how these differences influence the potential usage of telecare services. Mail survey was conducted in a medium-sized city to collect data. The target population was bit over 9,000 persons of which randomized sample were gathered. Total 556 usable responses were obtained for analysis. The results indicate that adoption behavior of individuals differs amongst potential telecare users. Indeed, the behavioral patterns do not stay constant over time. Therefore, understanding context of use has particular importance at the design phase of telecare services.
\end{abstract}




\section{$1 \quad$ Introduction}

In order to reduce pressures that modern societies face with their health and social care, the potential of technology-based services has widely bee accepted amongst academics and practitioners. Searching the role of telecare, telehealth and other e-service solution has been keen and directed to explore platforms of customer-driven services particularly for aging people. Significant amount of research directs to evaluate different technologies enabling longer span of living at home whilst the other side of the debate provides discourse on general needs of aging people. Regardless, the numerous articles published, there still is space for research which directs to analyse applicability of e-service concepts for specific user groups and to find out boundaries of domain of telecare within health care systems.

Telecare can be defined as a service bringing health and social care directly to a service user, generally in their own homes, supported by information and communication technology (Barlow, Curry, Wardle, Bayer and Trejo Tinoco, 2004). Telecare is meant to support independent living and welfare of older or disabled people. It involves the delivery of health and social care to individuals within the home or wider community outside formal institutional settings, with the support of systems enabled by information and communication technology (Bayer, Barlow and Curry, 2007). Based on the work of Barlow et al. (2006), the content of telecare includes safety and security monitoring, personal monitoring, electronic assistive technology, and information and communication solutions which also involve interaction. 
Aging people's need of support varies significantly between individuals and even day-to-day in one's life. Individuals' perceptions to their abilities to continue independent living at home can however be improved through appropriate technology interventions and redesigning living environment. Sufficiently adapted living environment with regard to ones functional capabilities has potential to motivate elders to perform challenging activities as long as possible (Fänge and Ivanoff 2009). Overall, sufficiently designed environment gives experience of self-efficacy to continue living independently. Fit in to daily routines and logical and reliable in use of self-care technologies are seen critical features of efficient technology interventions in elderly care (LeRogue 2011). The successful design of services begins from understanding habits of elderly to which service processes and interfaces are adapted. Therefore one general solutions cannot be defined which is major concern of service design requiring flexible and modular design.

Distress of individuals and care givers, and costly medical treatments in case of accident are the most remarkable concerns that physically or cognitively restricted elders faces (Monk et al. 2006). Technology interventions have potential to decrease consequences of limited functionality particularly in the area of cognitively restrictions where people with mild dementia can prolong the period of living at home environment (Davies et al. 2009). Implementation of smart homes to moderate disability processes of frailed-persons is not however straightforward, because ADL ("activities of daily living") disability has been observed to significantly correlate with depression and cognitive impairment which is likely to result anxiety to use technology (Kondo et al. 2008). With the growth of new technologies, it is important to explore the ability and willingness of customers to use these new technologies (Meuter, Ostrom, Bitner and Roundtree, 2003), and also apply existing technologies in services. To make technology useful to, and 
usable by older adults, a challenge for the research and design community is to "know the user" and better understand the needs, preferences and abilities of older people (Czaja and Lee, 2007).

In this article, we target to examine customers above 55 years, and especially how they differ regarding their physical, psychological and cognitive limitations. The central objective is the assess how these differences influence the potential usage of telecare services. The article provides empirical evidence to debate which we see increasing quality of current argumentation and criticism to e-solutions in heath care. Indeed, we connect demand-based customer segmentation to analysis of critical features of home care service of which will have more important position in the elderly care sector in future.

The article begins with discussion on platforms of smart home services which directs to enlighten dimensions of the analyzed service concept which applies novel technologies. Second, the main theories of behavioural intention are briefly referred and the selection of factors that influence innovation adoption is formed based on the target group and also in relation to the nature of telecare services. Third, we provide results of an empirical study which interlinks between users' characteristics, technology and intention to adopt technology based services.

\section{Smart homes as service delivery platforms}

The service delivery system can be understood as the unified model of a network where several actors produce value to the customer and each other (Normann and Ramírez 1993) and it 
contains an architecture for product, service and information streams between actors. From that basis we begin the critical review of the "e"-based solutions for the health care. Especially, the discussion targets to assess end-user related issues which influence on implementation of smart home constructs. Regardless of the buzz around the smart home and ubiquitous solution, no common definition exists at the moment. By definition of service provision model, a general construction of the smart home concept (see Figure 1) can be considered as a bundle of technologies, requisite services, and information and service provision resources which are delivered by a network of firms with different resources.

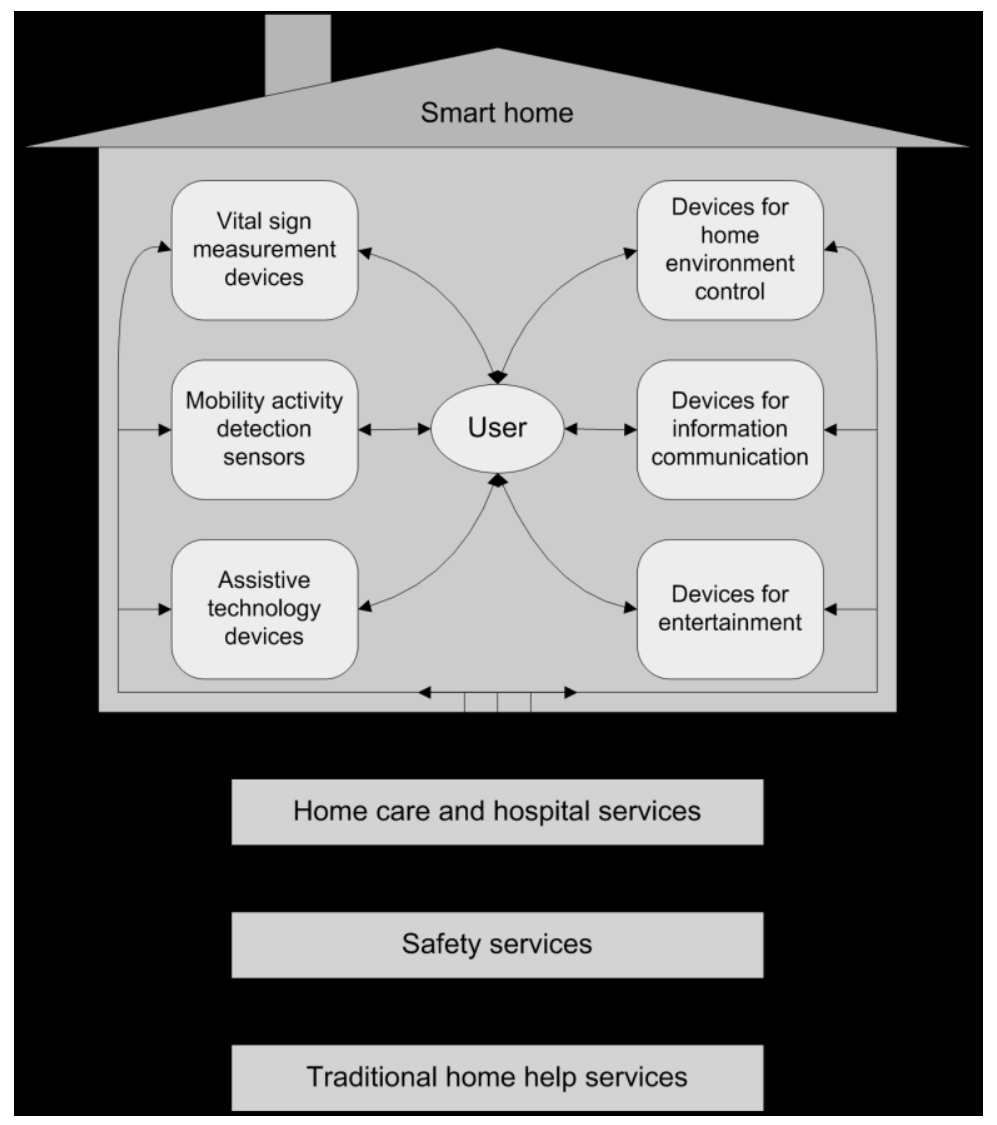

Figure 1 Illustration of a general smart home construct (adapted from(Chan et al. 2009)) 
The concept illustrates that smart homes can be approached from at least two views. The concepts are possible to define either as smart solutions at homes to support daily living or as solutions of which primary purpose is to provide a comfortable home environment. Furthermore some authors have provided more specific definitions regarding smart home concepts (see Table $1)$.

Table 1 Definitions for smart home

Source Definition

(Chan et al. 2009) Any living or working environment that has been carefully constructed to assist people in carrying out required activities.

(Cook and Das 2007) Acquires and applies knowledge about the environment and its inhabitants in order to improve their experience in that environment.

(Peine 2009)

Built entities in which various products and services interoperate by means of Information \& Communication Technologies (ICT) to constitute a product environment.

(Demiris et al. 2008)

Uses sensors and other devices and telecommunication features to enhance residents' safety and monitor their health and overall wellbeing.

(Nugent et al. 2008)

Monitors the activities of the person within their own living environment along with how they interact with home automation devices, and based upon these interactions and their current sequence of activities the ambient environment can be controlled and adapted to provide an improved living experience for the person.

The fundamental design strategies of smart home technologies and services $\mathrm{d}$ can be divided in two categories form elderly care perspective. The first category is self-care technologies which targets to provide enhancements to individuals self-confidence regarding ability to perform desired tasks which is particularly important factor to slow down activity decline (Fänge and Ivanoff 2009; Brokel, Cole and Upmeyer). The second category includes telecare solutions designed to compensate declined capacity to perform daily routines safely which include 
assistive devices, modifications in home environment and increasing awareness of elders on alternatives to perform tasks as well (Monk et al. 2006). Those perspectives are discussed in the following chapters

\section{Technology based services in elderly care}

\subsection{Contexts of use}

Design of smart homes is dependent upon personal needs and purpose of the acquired system through which requisite services and devices are to be selected. In general, use of ICT in older age segments has important role among three particular contexts (Salovaara et al. 2010):

(i) managing life transitions and maintaining social networks (e.g. retirement, moving new home),

(ii) (ii) overcoming transient events and

(iii) (iii) organizing daily tasks differently.

The first context includes group of activities which are targeted to provide easy access to community which could include messaging services and activation of individuals to meet peer groups, friends and families. However, face-to-face human contacts should be fostered regardless whether the smart homes are applied or not because technology itself do remove feelings of been separated from surrounding community. Some researches has presented findings that in the worst case technology rather demonstrates the social distance from others for aging people, or in best case novel solutions only moderate isolation process enabling stay in touch with friends and family (Salovaara et al. 2010; Dickinson and Gregor 2006). The skepticism to applicability of technology-based solutions are likely to arise particularly if outcomes are judged from perspective of customer segment which need support more than average persons in older age 
segments. The supportive activities of smart home environment are linked to second and third contexts where the services and devices solves functional restriction of individuals either temporal or permanent. The final portfolio of smart home services varies between user groups. Each solution must be tailored to fit customers' individual needs which can be evaluated though desired physical, cognitive, functional and social outcomes of technology intervention and fit of technology to the end-user's daily routines (Matthews et al. 2010). In this, it is worth to notice the importance of daily routines to indivuals' health status. Evidence has provided to assumption that the ability to perform daily routines is early indicator for increasing vulnerability and beginning of disablement process in old age before deceases are clinically diagnosed (Fänge and Ivanoff 2009). Technology interventions have several effects in the early stages of disablement. Technology can remove some obstacles of functionality of frailed-persons or restore functionality to requisite level. Indeed, beginning of disablement process can be prevented amongst temporally disabled persons by technology interventions. Overall, most of the potential of smart homes are therefore involved with solutions that are directed to enhance ability of elders which functionality reflects early-sings of disablement. Based on fact that early-indicators of disablement differs between people, implementing smart home solutions in large-scale requires solution ready concepts and mass customization of platforms.

\subsection{Theoretical background and hypothesis for the adoption intention of telecare services}

Approaching willingness to adopt new service can be done by analyzing the market due to consumers' intention adopt or start using new services. The interest behind studying originates from the theory of planned behavior (TPB) (Ajzen, 1991) and technology acceptance model (TAM) (Davis, 1985) that both are based on the premise that intention is a good predictor of 
actual behavior. These theories have been widely used, modified, and complemented in innovation adoption research depending on the research target.

\subsubsection{Service innovation related characteristics}

Innovation adoption depends on the attitude formation of individual perceptions related to innovation characteristic. From perceived innovation characteristics, perceived usefulness from TAM has often been used when modeling consumer intentions, and according to Salovaara et al. (Salovaara et al. 2010) the willingness to apply technology among senior citizens depends strongly on its perceived usefulness. In practice, the contribution of technology to issues in daily life is noticed critical factor for acceptance (Mitzner et al. 2010; Heart and Kalderon). The perceived usefulness of technology in the analyzed context is defined through one's ex-ante judgment of perceived benefits, sacrifices and discomfort of use which are dependent on skills to use ICT on daily-life, previous experiences on technology use influences and on one's attitudes to technology. Recent studies to older age segments from ICT use perspective has shown that economical aspects would not be significant factor to explain adoption of new technologies if benefits of technology for a user are well demonstrated (Heart and Kalderon). However, economical reasons are reported creating obstacles to access to ICT amongst low income elderly to which can probably be influenced by developing governmental subsidies or other forms of financial support (Lee, Chen and Hewitt 2011; LeRouge et al.; Carpenter and Buday 2007). In case of electronic services, previous research has verified that perceived usefulness is an important element defining intentions to adopt new services (e.g. Gefen, Karananna, Straub, 2003a; Chan \& Lu, 2004; Hong, Thong, \& Tam, 2006), and therefore the first proposed hypothesis is:

Hypothesis 1: Perceived usefulness increases intention to adopt telecare services. 
Electronic services related to health always contain transmission of personal information, which can be considered to raise questions of risks related to service reliability and privacy protection. Perceived risk can take many forms, depending on the product and consumer characteristics (Chan and Lu, 2004), and according to Walker and Johnson (2006) perceived risk has two main elements related to technology enabled services. The first concerns the technical performance or functional reliability of the service delivery systems, and the second concerns issues of personal privacy and security. These are related to the absence of human contact during the service delivery process and the performance of the service delivery system. In contrast to the perception of risk, research has shown that in the internet environment trust perceived toward the counterparty is important for behavioural intentions (Gefen et al., 2003a; Gefen, Karahanna and Straub, 2003b). When considering consumers using electronic health care services, their perceptions of information security can be suggested to prompt adoption or rejection. Previous research discusses information security under concepts of perceived reliability, security and privacy. For instance, privacy attached to online shopping as defined by Vijayasarathy (2004) means the extent to which a consumers believes that shopping online will not compromise his/her privacy and security as the extent to which a consumer believes that making payments online is secure. This type of concern related to privacy is essential for online health services whether or not payments are included. Reliability aspect was referred in the study of Lee, Lee, \& Eastwood (2003) as the degree to which a consumer believes that a new technology will perform a job consistently and accurately and in the same study perceived security concern indicated concerns about transaction security in terms of cyber crime or errors in transactions. This kind of security includes the aspects of feeling safety when transmitting personal information through 
the network, and is thus important for the present study. Including privacy concerns, the second hypothesis is:

Hypothesis 2: Perceived reliability increases intentions to adopt telecare services.

\subsubsection{Personal attitudes related to ICT}

Roughly, the adoption of e-services has two core parts: the service itself (which has already been discussed) and the device through which the service is used. The attitudes and perceptions toward the service influence adoption decision, but also the attitudes and perceptions related to the devices are important, because the target market has to have the necessary knowledge and capabilities that are required for reaching the maximum benefits of the service. Considering aging people as the target market for a new e-health application, it has to be reminded that this population has grown in the world without computers, mobile phones and internet. In addition, a large share of elderly consumers is not familiar with these technologies from their work life, and therefore the learning how to use the required technologies is based on voluntary choices. Typical for elderly adopting innovations is the fear that it will not perform as desired (Lunsford and Burnett, 1992). This kind of functional risk increases along with the technological complexity of an innovation. Among older consumers and technology, a common issue under research is the fear for technology, i.e. technology anxiety. According to Meuter et al. (2003), technology anxiety focuses on the user's state of mind regarding their ability and willingness to use technology-related tools. In the information technology research the focus has been on computer anxiety. According to Izard and Tomkins (1966), anxiety in general can be seen as a negative affect that tends to be sensed as noxious and difficult to tolerate and to instigate avoidance of and/or nonconstructive relations with the object. Technology anxiety originates 
from computer anxiety which has been defined as emotional fear, apprehension and phobia felt by individuals towards interactions with computers or when they think about using computers (Chua, Chen and Wong, 1999), referring to the negative attitudes toward using the computer. Likely the anxiety rises from the inability or lack of self-confidence in effectively managing or controlling the technology (Oyedele and Simpson, 2007). Computer attitudes in a general level have appeared to be good predictors of computer understanding and experience (Potosky and Bobko, 2001), and it also decreases the subjects' expectations and confidence of performing computer related tasks (Glass and Knight, 1988). Technology anxiety therefore is one remarkable factor to how likely individual user judges the new technology-based services useful and valuable. Former experiences to use of internet consistently have proven to correlate with computer anxiety of older age segments which provide one method to evaluate behavior of an individual (Jenni Niemelä-Nyrhinen 2007). Technology anxiety concerning appliances used for e-services can therefore be seen as an inhibitor of new service adoption. On the other hand, suspicious attitudes related to computers might also complicate the perceptions related to usefulness and especially the reliability of services, and therefore it is hypothesized that:

Hypothesis 3: Technology anxiety decreases perceived usefulness of telecare services.

Hypothesis 4: Technology anxiety decreases perceived reliability of telecare services.

Considering that ICT might be quite novel for aging consumer, the avoidance related to technology might also be related to the design and interface of the device in terms of physical elements. Behavioral intention in TPB includes a determinant of perceived behavioral control, that refers to to people's perception of the ease or difficulty of performing the behaviour of interest (Ajzen, 1991) and is formed from control beliefs and facilitation. Besides attitudinal 
control related to person's knowledge, the physical capabilities of an aging individual cannot be neglected. The lack of these capabilities can rise for example from physical impairment or poor sight, and can therefore form physical restrictions that decrease the willingness to use ICT or even completely make the use of ICT impossible. Frailed-persons have proven to have lack of intension to adopt ICT because of lower perceived behavioral control over ICT due to physical restrictions (Heart and Kalderon). Therefore, smart home system interfaces should not include numerous visible options, functions should not require complex tasks and overall desing must emphasize intuitive activities. The device dependent physical limitations are therefore assumed to decrease intention to adopt e-services, and decrease the level of usefulness and reliability related to the services, thus the hypotheses are:

Hypothesis 5: Physical restrictions decrease perceived usefulness of telecare services.

Hypothesis 6: Physical restrictions decrease perceived reliability of telecare services.

\subsubsection{Individual characteristics of elderly}

Aging has psychological, biological, social and economic influences on consumers (see Pak \& Kambil, 2006). Biological changes cover changes in mobility, vision and hearing, which all influence daily customs. For service developers the biological issues create challenges for product and service designs and communication methods. Changes in memory and information processing result in declining rate of learning and avoiding situations that aren't familiar. People age differently and aging itself is a multidimensional process. Differences in consumer responses among older people are not likely to be the result of any specific factor, and the processes of aging are manifested in differences in attitudes and behaviors even among people of the same 
age (Moschis,1992). Research has found that neither cognitive nor chronological age are determinants of innovativeness among the elderly (Szmigin \& Carrigan, 2000). Vuori \& Holmlund-Rytkönen (2005) found similar results in their study of 55+ internet users. Cognitive age had no relationship with internet use; instead, health was found to be a predictor of internet use. As the need of care services is strongly bound to perception of health and functioning, the aging market is divided to high need consumers (frail elderly) and low need consumers (wellcoping elderly), the final hypotheses are:

Hypothesis 7: Personal attitudes related to ICT have weaker effect on service perceptions among well-coping elderly.

Hypothesis 8: Service perceptions have stronger influence on intention among well-coping elderly.

\section{$4 \quad$ Method}

\subsection{Sample and demographics}

The empirical evidence was collected using a cross-sectional mail survey that was targeted to 55-79-year-old inhabitants in a medium-sized city located in the South-Eastern part of Finland. The total target population was a bit over 9,000 persons. A stratified random sample of 1,000 people was drawn from the Finnish Population Register. The sample frame was conducted based on the population age distribution divided in five-year categories. Totally, 556 responses were received and the resulted age distribution was representative indicating no statistical difference compared to the true age distribution in the population (Figure2). Gender was also in line with 
the target population; the share of female respondents was 56.8 percent ( 54.4 in the population). The data consisted mainly of individuals living independently in the community, as only 1.5 percent received public homecare assistance and that share was the same in the target population.

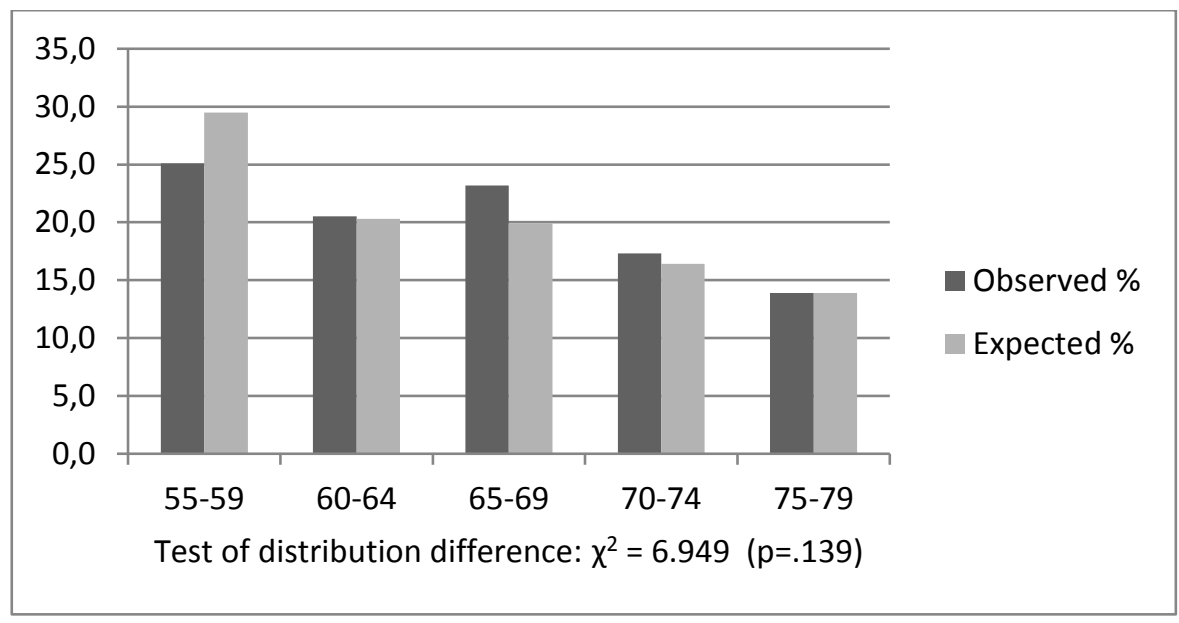

Figure 2 Age distribution of the respondents versus population

\subsection{Research model, key concepts and measurement}

Figure 3 illustrates the research model with the hypotheses and thus also gathers the key concepts essential for the empirical study. 


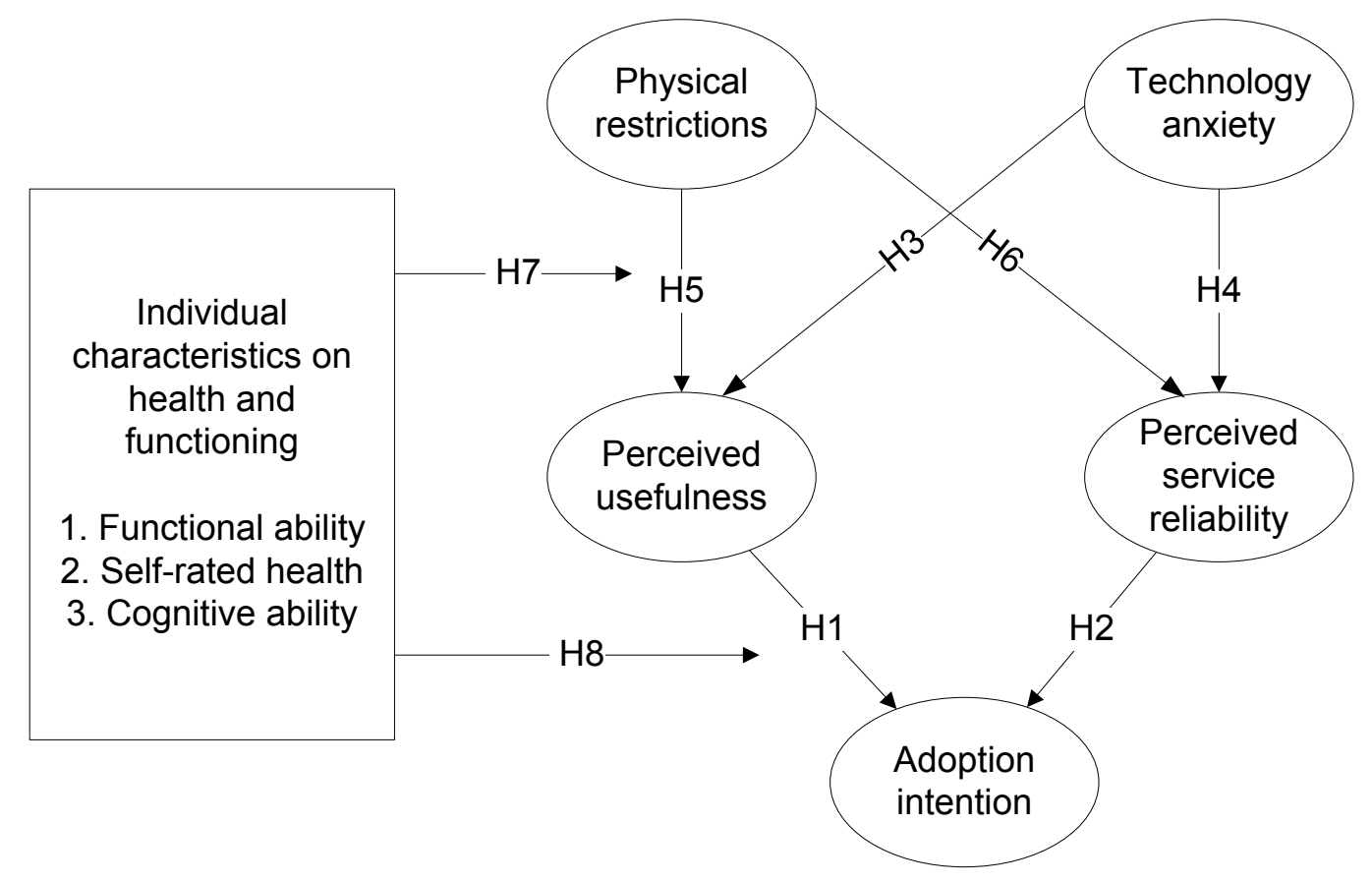

Figure 3 Key concepts and research model

The measurement included multi-item scales that were mainly gathered from previous literature and modified to fit the content of the research. The scales were kept as short s possible in order to make the filling of the questionnaire easier and preventing the frustration among the respondents. All items (if not otherwise reported) were statements measured with a 5-point Likert scale varying from completely disagree to completely agree.

Health and functioning was included for the purposes of dividing elderly into two groups. This actually covered dimensions of self-rated health status, cognitive functioning and functional ability.

Functional ability was measured using similar methods as previous research (Verbrugge and Yang, 2002) including the basic activities and instrumental activities of daily living. The items 
were measured with a three point ordinal scale $(1=$ cannot cope at all, $2=$ has difficulties, $3=$ copes independently). Eventually, the scale of functioning was composed of five indicators of coping with instrumental activities of daily living (small repairs, shopping, house cleaning, cooking and washing) due to the low variance in the basic activities of daily living.

Self-rated health was measured with a global measure for self-rated health (Jelicic and Kempen, 1999; Vaez, Kristenson, \& Laflamme, 2004). It had five response alternatives varying from poor to excellent. This measure of self-rated health is a non-comparative measure that indicates the perception of current state of health, and it is widely used in research of self-rated health. In order to form a multi-item scale and thus increase the reliability compared to one item measurement, the global measure of self-rated health was complemented with three additional statements.

Cognitive ability was considered important for the purposes of this research because information technology based service require learning and memory capabilities. Two measurement items selected to cover the level of cognitive capacity were drawn from the cognitive factor of Zung Self-Rating Depression Scale (Passik, Lundberg, Rosenfeld, Kirsh, Donaghy, Theobald et al., 2000).

Technology anxiety related to ICT was measured with items modified from computer anxiety. Different scales of computer attitudes and computer anxiety were compared in order to elaborate an effective but reasonably short and valid measurement for technology anxiety. The four selected items covered such elements as fear, uncomfort and embarrassment that have been part of the scales used in previous research (e.g. Loyd and Gressard, 1984; Loyd and Loyd, 1985; 
Cohen and Waugh, 1989; Brock and Sulsky, 1994; Kinzie, Delcourt, \& Powers, 1994; Selwyn, 1997; Shaft, Sharfman, \& Wu, 2004).

Perceived physical restrictions for using ICT were reflected with two statements. The items discussed the usage difficulties related keyboard and the size the screen.

Perceived usefulness was measured with four statements adopted from Venkatesh, Speir, \& Morris (2002). The items were roughly modified for the purposes of present study.

Perceived reliability included four items that were modified from the study of Lee et al. (2003), concentrating on privacy issues in sending and receiving personal information.

Intention had two items adapted from Venkatesh et al. (2002).

Table 2 summarizes the measurement of the key concepts that was based on a latent factor structure.The measurement model was verified with confirmatory factor analysis and the reliabilities were assessed with composite reliability (CR) and level of average variance extracted (AVE) which both are based on factor loadings and error variances (see e.g. Fornell \& Larcker, 1981 and Diamantopoulos \& Siguaw, 2000). All of the produced constructs had high level of reliability as well as an excellent share of variance explained by the latent construct. The analysis represented next will report summated statistics represented by the mean values computed from the individual items. 
Table 2 Measurement reliabilities

\begin{tabular}{lccc}
\hline Concept & N of items & CR & AVE \\
\hline Functional ability & 5 & .916 & .652 \\
Self-rated health & 4 & .853 & .510 \\
Cognitive ability & 2 & .866 & .767 \\
Technology anxiety & 4 & .850 & .521 \\
Physical restrictions & 2 & .902 & .822 \\
Perceived usefulness & 4 & .905 & .705 \\
Perceived reliability & 4 & .890 & .669 \\
Adoption intention & 2 & .901 & .822 \\
\hline
\end{tabular}

\subsection{Research procedure}

The research process of this study consists of two parts. In the first part of the empirical study, we aim to segmenting the target population based on self-rated health status, functioning and cognitive ability. The need based segments were formed with clustering, applying the k-means clustering technique with IMB SPSS software. The second part of the empirical analysis consists of structural equation modelling for testing the proposed hypothesis using LISREL. For the structural model, polychoric correlations with asymptotic covariances were used as input data due to the ordinal nature of the variables (Olsson, 1979; Rigdon, 1998). The estimation method was unweighted least squares, which has no assumptions about the distribution of observed variables (Long, 1983). The modelling uses a multi-group analysis approach, and applies the segmentation results as the basis for dividing the elderly into need based segments. Before testing the hypotheses, the measurement invariance was verified. This means that the confirmatory factor analysis was conducted simultaneously for both groups produced with the clustering (e.g. Byrne, 1998). The procedure included phases of 1) structural invariance 
(composition of the measurement model is the same in both groups), 2) metric invariance (equal factor loadings in both groups) and 3) factor variance invariance (Steenkamp \& Baumgartner, 1998; Atienza, Balaguer \& Garciá-Merita, 2003; Byrne \& Miller, 2009). The reliabilities were in addition evaluated across groups, that also supported the invariance of the measurement.

\section{$6 \quad$ Results}

\subsection{User segments}

The basic idea behind the segmentation was to distinguish two groups of elderly that differ in relation to functioning, cognition and perceived health as the presumption is that smart home systems should be designed to match the customer needs. The two groups that were obtained are onward referred as "frail" and "well-coping" elderly. Table 3 provides the cluster means and standard deviations as well as the statistical results for group wise differences. Due to incomplete responses the effective sample used in the analysis was 506.

Table 3 Descriptive information of clustering variables

Frail elderly $(N=184)$

Segmentation variable

Functional ability*

Self-rated health*

Cognitive ability*
Mean

2.35

2.42

2.83
Std.dev.

.622

.701

1.091
Well-coping elderly $(\mathrm{N}=322)$

Mean

Std.dev.

2.88

3.84

3.98
.294

.662

1.076

*mean difference significant at $\mathrm{p}<.001$ 
Descriptive information of the group demographics are in Table 4. The group of frail elderly includes a bit older individuals. The difference is statistically significant at $p<.001$. This is natural, due to the aging process, but considering the standard deviation of age, both groups have quite high variation in terms of age. Well-coping elderly include almost an even share of men and women, whereas the share of women rises with age (women living longer than men) and this can be seen in the gender distribution of the frail elderly. This same trend can be seen when considering the marital status, the share of people living alone rises due to the increased share of widowed people.

Table 4. Segment demographics

\begin{tabular}{llcc}
\hline & & Frail elderly & Well-coping elderly \\
\hline Age & Mean & 66.80 & 64.46 \\
& Std.dev. & 7.21 & 6.40 \\
\hline Gender & Male & $65.20 \%$ & $51.50 \%$ \\
& Female & $34.80 \%$ & $48.50 \%$ \\
\hline Marital status & Living with a spouse & $67.70 \%$ & $73.10 \%$ \\
& Single & $7.00 \%$ & $5.10 \%$ \\
& Divorced & $10.40 \%$ & $10.30 \%$ \\
& Widowed & $14.90 \%$ & $11.50 \%$ \\
\hline
\end{tabular}

Technology perception were assessed between the segments (Table 5). Interestingly, the level of anxiety and perceived physical restrictions were the only source of difference between the groups. Frail elderly perceived the level of technology anxiety higher than the well-coping elderly. In addition, the perceived physical barriers related to using technology were clearly causing more problems for frail elderly. 
Table 5. Mean comparison of the technology perceptions between the segments

\begin{tabular}{lcccc}
\hline & Frail elderly & \multicolumn{2}{c}{ Well-coping elderly } \\
Technology perceptions & Mean & Std.dev. & Mean & Std.dev. \\
\hline Technology anxiety* & 1.96 & 0.994 & 1.57 & 0.770 \\
Physical restrictions* & 3.36 & 1.305 & 2.63 & 1.350 \\
Perceived usefulness & 3.78 & 0.997 & 3.80 & 1.004 \\
Perceived reliability & 3.46 & 1.068 & 3.58 & 1.064 \\
Adoption intention & 3.61 & 1.137 & 3.67 & 1.237 \\
\hline *mean difference significant at $\mathrm{p}<.001$ & & & \\
\hline
\end{tabular}

\subsection{Structural model to explain}

Before testing the hypothesis with a structural model, the measurement invariance was confirmed for the segments. Measurement invariance was achieved indicating that the factor loadings, intercepts and residual variances across the groups are same. Because the numbers of observation was a bit inadequate for using the full latent factor structure in the path analysis, summated scales were applied instead by computing indicator error variances from the summated scale variance and composite reliability (see e.g. Fisher \& Price, 1992; Childers, Carr, Peck, \& Carson, 2001). Table 6 summarizes the results of the modelling. The model itself produced excellent goodness of fit to the data. For each path, the standardized path coefficient is reported with its level of significance. The first part of the table (unrestricted model) gathers the results of the basic model estimated separately for both groups. The second part of the table 
(restricted model) includes the results of the comparison of the path coefficients across the groups.

Starting from the first hypothesis (H1) that intention is positively influenced by perceived service usefulness; the results support this hypothesis for both groups. A high and positive coefficient suggests that intention is strongly dependent on service usefulness. The same conclusion can be made for the second hypothesis (H2), as perceived service reliability also has a high and positive influence on intention. What comes to the current technology in terms of restriction and anxiety, the results are not congruent across the segments. Hypotheses $\mathrm{H} 3$ and H4, discussed the effect of technology anxiety on new service perceptions. The only significant effect was found in the path from anxiety to reliability in the group of frail elderly, thus the hypothesis H3 is restricted and $\mathrm{H} 4$ is partly supported by the data.

Table 6. Results of the modeling

\begin{tabular}{|c|c|c|c|c|c|c|c|}
\hline \multicolumn{6}{|c|}{ Unrestricted model } & \multicolumn{2}{|c|}{ Restricted model } \\
\hline Hypoth. & Path & & & Frail & coping & Hypoth. & $d \chi^{2}(\mathrm{ddf}=1)$ \\
\hline H1 & Service usefulness & $\rightarrow$ & Adoption intention & $.682 * * *$ & $.828^{* * *}$ & $\mathrm{H} 8$ & $7,29 * *$ \\
\hline $\mathrm{H} 2$ & Service reliability & $\rightarrow$ & Adoption intention & $.624 * * *$ & $.728 * * *$ & H8 & $5,01 *$ \\
\hline H3 & Technology anxiety & $\rightarrow$ & Service usefulness & -.0790 & -.066 & $\mathrm{H} 7$ & .020 \\
\hline H4 & Technology anxiety & $\rightarrow$ & Service reliability & $-.145^{* *}$ & -.073 & $\mathrm{H} 7$ & .500 \\
\hline H5 & Physical restrictions & $\rightarrow$ & Service usefulness & $-.153 * *$ & -.055 & $\mathrm{H} 7$ & .930 \\
\hline H6 & Physical restrictions & $\rightarrow$ & Service reliability & $-.207 * * *$ & $-.120 *$ & $\mathrm{H} 7$ & .830 \\
\hline
\end{tabular}


${ }^{*} \mathrm{p}<.050,{ }^{* *} \mathrm{p}<.010,{ }^{* * *} \mathrm{p}<.001$

Hypotheses H5 and H6, concentrated on the physical restriction that occur when using ICT. From these, only H6 is completely supported indicating that physical restrictions decrease the perceived reliability of new services. The decreasing effect of physical restriction on service usefulness is significant only among frail elderly, thus H5 is partly supported.

The next step in the analysis was to examine whether the path coefficients estimated in the unrestricted model are statistically the same across the groups (H7 and H8). In order to test the assumptions, each of the paths was in turn forced to be the same across the groups. This means that when estimating the model, the path for instance from usefulness to intention was not freely estimated for both groups. Instead, the path for frail elderly was assumed to be the same as estimated for the group of well-coping elderly. The change in the model khi square is used as an indicator of the model deterioration if the paths of the groups differ significantly from each other. Hypothesis H7 didn't find any support when the paths of current technology anxiety and physical restrictions were fixed to be the same. However, statistically significant decrease in model fit occurred when the paths from technology perceptions were forced to be the same across groups. This indicates that the hypothesis H8 can be supported, thus the positive influence of service reliability and usefulness is stronger among well-coping seniors. 
Table 7. Standardized indirect effects

\begin{tabular}{lllll}
\hline Indirect effects & & & Frail & Well-coping \\
Technology anxiety & $\rightarrow$ & Adoption intention & $-0,159 * *$ & $-0,074$ \\
Physical restrictions & $\rightarrow$ & Adoption intention & $-0,258 * * * *$ & $-0,122 *$ \\
\hline${ }^{*}<.100,{ }^{* *} \mathrm{p}<.050, * * * \mathrm{p}<.001$ & & \\
\hline
\end{tabular}

In addition, to understand the complete effects of current technology attitudes, the indirect effects of physical restrictions and anxiety were estimated for the model. Table 7 includes the standardized estimates of the indirect effects of technology anxiety and physical restrictions on usage intention. The decreasing effect of technology anxiety on willingness to use new services was significant only among frail elderly. The indirect effect of physical restrictions was negative and significant in both groups.

\section{$7 \quad$ Discussion}

The purpose of the study was to analyze how different customers form their attitudes and usage intention toward telecare services. Indeed, the customer base that was in the research target formed two distinguished categories: one that included well-coping elderly, and one consisting of frail elderly that have tendency for limited functioning related to daily activities and cognition. When this information was attached to the model composed for explaining usage intention of telecare services, the results suggest that differences exist between these two customer segments. The overall results suggest that attitudes related to usage of ICT influence the perceptions formed toward new services. Considering the results from statistical point of view, these effects were the 
same across customer segments. However, the difference between the segments occurs with the perceived service characteristics and how they influence the usage intention.

If taking a look at the results of the unrestricted model as a whole, it can be seen that the attitudes related to ICT have significant effects to new service perceptions among frail elderly (although the difference between the groups is statistically insignificant). Technology anxiety causes insecurity only among frail elderly and indirectly therefore inhibits new service adoption. Also the physical restrictions related to ICT use have stronger negative effects on new service reliability and usefulness among frail elderly. Together anxiety and restrictions are sources of uncertainty, and therefore also the potential benefits are harder to perceive. For the whole sample, our results indicate that higher physical restrictions significantly causes the new services perceived as less reliable, which is important due to the fact that telecare services are mainly targeted for aging market, and if services are designed to be interactive and require the customer to be an active participant in using the service, the interface and device design should support easy access and unrestricted usage. As the level of usage intention is the same for both groups, the perceived service characteristics have lower effect on intention for the frail group. This also supports the conclusion that current experiences with ICT might inhibit the adoption of new services.

The smart homes are not bounded only ICT devices and systems, but they should be considered as appropriately designed living environment particularly if the user has ADL limitations. People with impaired competencies are sensitive to environment regarding their independence, which could be supported with appropriate manipulations (Wherton and Monk 2008). For instance, the 
technologies can impose limitations resulted from chronic deceases especially if the devices support timing of daily activities (e.g. visual sings) in the case of memory disorders (Monk et al. 2006). Indeed, the perceptions on functionality of environment and self-confidence in new circumstances differs in cognitively impaired people compared to healthy subjects (van Hoof et al. 2010). The previous view to system design process has lacked in many smart home concepts which approaches smart homes environment form non-physically restricted people perspective.

Recent researches on elderly care emphasize positive outcomes of opportunity to continue living at home to individual's health because it supports activity and participation in community (Fänge and Ivanoff 2009). Health has also positive influences on attitudes to learning and adopting new routines into their daily activities. Indeed, healthy person are more likely to begin use of technology based-service if technologies will increase independence and delay need for regular nursing. The key outcomes of this study are summarized in the Table 8 and discussed in following chapters.

\section{Theoretical implications}

The present research contributes to the existing literature of innovation adoption and behavioral intention. The specified behavioral model was fitted well for aging market. In addition, the research extends information that previous research has introduced as the focus of the research were the end-user consumers. The results also indicate that individuals belonging to the same market do not necessarily have the same kind of adoption behavior when new services are introduced. This means that factors that either facilitate or inhibit innovative service aren't first of all the same across the market neither their effect is consistent. The market that consists of 
aging people has possibly several diverging segments in which the behavior has different features.

\section{Practical implications}

Technology anxiety of a person does not necessarily stay constant over time. Referring to research made related to computer anxiety, it has been found to be a sort of state anxiety that can be changed (Chua et al., 1999). This reflected to technology means that the level of anxiety can be altered by proper training targeted correctly for the individual's level of knowledge and abilities. Privacy concerns regarding ICT have seen to increase resistance and anxiety to adopt new services life if users do not understand how services functions or security policies are inappropriately communicated. Therefore education and training are important factors to increase utilization of ICT amongst elderly segments, which have influences on efficiency of service from perspective of users and service providers (Mitzner et al. 2010; Carpenter and Buday 2007). The devices and services targeted to alleviate functional restriction must be designed easy to learn and use in the given circumstances which set requirement particularly for user interfaces. The physical restriction might be impossible to overcome when the functioning and the level of cognition decreases, however the interactive part of telecare must then include different types of services (monitoring etc.). Finally, familiarity of technology for users is important factor when one judges reliability and usefulness of new services. That feature has particular meaning amongst users with limited cognitive ability which emphasize pre-emptive role of telecare in health care rather than its preventive effects for acute care. 


\begin{tabular}{|c|c|c|c|}
\hline $\begin{array}{l}\text { Theorethical Contribution - } \\
\text { Attributes influencing adoption of } \\
\text { eHealth }\end{array}$ & \multicolumn{2}{|c|}{ Key empirical findings regarding particular user segments } & Practical implications \\
\hline $\begin{array}{l}\text { Users } \\
\text { Functional and cognitive ability, } \\
\text { and perceived health status } \\
\text { differentiates user groups. }\end{array}$ & $\begin{array}{l}\text { Frailed elderly } \\
\text { The segment represents elderly of low } \\
\text { self-rated health and decreased } \\
\text { cognitive ability. Functional ability is } \\
\text { tend to decrease in this group. }\end{array}$ & $\begin{array}{l}\text { Well-coping elderly } \\
\text { The segment represents elderly of } \\
\text { high self rated health and good } \\
\text { cognitive ability. Significant changes } \\
\text { from normal functional ability cannot } \\
\text { be recognized. }\end{array}$ & $\rightarrow \begin{array}{l}\text { Market of aging ICT users is not } \\
\text { homogeneous by adoption } \\
\text { behavior of new service. }\end{array}$ \\
\hline $\begin{array}{l}\text { Technology } \\
\text { Physical restrictions and } \\
\text { technology anxiety influence } \\
\text { attitudes to and willingness to use } \\
\text { technology which varies between } \\
\text { user groups }\end{array}$ & $\begin{array}{l}\text { Physical restrictions negatively } \\
\text { correlate with perceived usefulness } \\
\text { and reliability of new services. } \\
\text { Technology anxiety diminishes } \\
\text { perceived reliability of technology } \\
\text { based services. }\end{array}$ & $\begin{array}{l}\text { Correlation between personal } \\
\text { attitudes to technology and } \\
\text { perceived usefulness and reliability } \\
\text { did not found excluding negative } \\
\text { influence of physical restrictions. }\end{array}$ & $\begin{array}{l}\text { Technology anxiety can be } \\
\text { altered by proper training which } \\
\text { fit into knowledge and abilities } \\
\text { aging users. } \\
\text { Providing proper information on } \\
\text { security increase rate of ICT } \\
\text { adoption amongst well-coping } \\
\text { elderly }\end{array}$ \\
\hline $\begin{array}{l}\text { Service } \\
\text { Intention to adopt eHealth } \\
\text { services correlates with perceived } \\
\text { usefulness and perceived } \\
\text { reliability of service. The } \\
\text { influences are not stable over user } \\
\text { segments. }\end{array}$ & $\begin{array}{l}\text { Perceived usefulness and reliability of } \\
\text { technology based services increase } \\
\text { intention to adopt new services. } \\
\text { However, influence is weaker than } \\
\text { amongst well coping elderly. }\end{array}$ & $\begin{array}{l}\text { Perceived usefulness and reliability of } \\
\text { technology based services increase } \\
\text { intention to adopt new services. } \\
\text { The influence in this group was } \\
\text { recognized statistically stronger than } \\
\text { amongst frailed elderly. }\end{array}$ & $\begin{array}{l}\text { Interfaces must be designed easy } \\
\text { to learn and use particularly if } \\
\text { users have functional or cognitive } \\
\rightarrow \text { restriction } \\
\text { Interactive services (monitoring) } \\
\text { can support daily living of } \\
\text { physically restricted elders. }\end{array}$ \\
\hline $\begin{array}{l}\text { Indirect influences } \\
\text { Both physical restriction and } \\
\text { technology anxiety has } \\
\text { statistically significant indirect } \\
\text { influences on intention to adopt } \\
\text { technology based services. }\end{array}$ & $\begin{array}{l}\text { Physical restrictions were recognized } t \\
\text { indirect influence on intention to adop } \\
\text { eld } \\
\text { Anxiety has negative influence on ado } \\
\text { of fraile }\end{array}$ & $\begin{array}{l}\text { have statistically significant negative } \\
\text { eHealth service amongst well-coping } \\
\text { rly. } \\
\text { tion intention particularly in segment } \\
\text { elderly. }\end{array}$ & $\begin{array}{l}\text { Alleviating physical restriction of } \\
\text { individuals has positive effects to } \\
\text { intention to adopt telecare } \\
\text { services. } \\
\text { Familiarity of telecare amongst } \\
\text { users with limited cognitive } \\
\text { ability is remarkable factor for } \\
\text { acceptance of new services. }\end{array}$ \\
\hline
\end{tabular}




\section{Research limitations and future research directions}

As the study is cross-sectional, it is unable to clarify how sensitive the technology perceptions are for changes in health conditions or how they could have been changed. The usage of selfreported measures composes also a risk for common method bias, but on the other hand several concepts used in this research are purely subjective and there would not have been any other way to conduct the measurement. In addition, the formation of the questions related to telecare services were based on quite hypothetical situation, as no concrete telecare services were in the market at the time of the study. This might results a bit too high level of usage intention as the respondents couldn't refer to previous experiences of related services.

However, this results interesting topics for future research. The new services that are about to be launched could be used as an important cases that provide information related to true perceptions of service usefulness and reliability, as well as how the pre-assumption related to the capabilities to use the new services has interfered the adoption process. If possible, this type of study would be useful in a post-adoption situation which would make it possible to analyze the true effect of perceptions on intention, as well as how the experiences have changed the attitudes. On the other hand, concerning service providers, the research is also need on how the differing end-user requirements are taken into account in the design process of service entities. This study has particular interest to explain intention to use telecare services, but utilizing similar research settings to other care services further can provide valuable insight to service design in general. 


\section{References}

Ajzen, I. (1991). The Theory of Planned Behavior. Organizational Behavior and Human Decision Processes, 50, 179-211.

Atienza, F.L., Balaguer, I., \& Garcrá-Merita, M.L. (2003). Satisfaction with Life Scale: analysis of factorial invariance across sexes. Personality and Individual Differences, 35, 1255-1260.

Barlow, J., Curry, R., Wardle, D., Bayer, S., \& Trejo Tinoco, M. (2004). Implementing Telecare: Strategic analysis and guidelines for policy makers, commissioners and providers. In Public Sector National Report. London: Audit Commission.

Bayer, S., Barlow, J., \& Curry, R. (2007). Assessing the Impact of a Care Innovation: Telecare. System Dynamics Review, 23(1), 61-80.

Brock, D.B., \& Sulsky, L.M. (1994). Attitudes toward Computers: Construct Validation and Relations to Computer Use. Journal of Organizational Behavior, 15(1), 17-35.

Brokel, J.M., Cole, M. \& Upmeyer, L. "Longitudinal study of symptom control and quality oflife indicators with patients receiving community-based case management services", Applied Nursing Research, vol. In Press, Corrected Proof.

Byrne, B.M. (1998). Structural equation modeling with LISREL, PRELIS, and SIMPLIS: Basic concepts, applications, and programming. New Jersey: Lawrence Erlbaum Associates.

Byrne, Z.S., \& Miller, B.K. (2009). Is justice the same for everyone? Examining fairness items using multiple-group analysis. Journal of Business Psychology, 24, 51-64.

Carpenter, B.D. \& Buday, S. 2007, "Computer use among older adults in a naturally occurring retirement community", Computers in Human Behavior, vol. 23, no. 6, pp. 3012-3024.

Chan, M., Campo, E., Estève, D. \& Fourniols, J. 2009, "Smart homes - Current features and future perspectives", Maturitas, vol. 64, no. 2, pp. 90-97.

Chan, S.-C., \& Lu, M.-T. (2004). Understanding Internet Banking Adoption and Use Behavior: A Hong Kong Perspective. Journal of Global Information Management, 12(3), 21-43. 
Childers, T.L., Carr, C.L., Peck, J., \& Carson, S. (2001). Hedonic and Utilitarian Motivations for Online Retail Shopping Behavior. Journal of Retailing, 77, 511-535.

Chua, S.L., Chen, D.-T., \& Wong, A.F.L. (1999). Computer Anxiety and Its Correlates: A MetaAnalysis. Computers in Human Behavior, 15(5), 609-623.

Cohen, B.A., \& Waugh, G.W. (1989). Assessing Computer Anxiety. Psychological Reports, 65, 735-738.

Cook, D.J. \& Das, S.K. 2007, "How smart are our environments? An updated look at the state of the art", Pervasive and Mobile Computing, vol. 3, no. 2, pp. 53-73.

Czaja, S.J., \& Lee, C.C. (2007). The Impact of Aging on Access to Technology. Universal Access in the Information Society, 5(4), 341-349.

Davis, F.D. (1985). A Technology Acceptance Model for Empirically Testing New End-User Information Systems: Theory and Results. Unpublished doctoral disseration, Massachusetts Institute of Technology, Massachusetts.

Davies, R.J., Nugent, C.D., Donnelly, M.P., Hettinga, M., Meiland, F.J., Moelaert, F., Mulvenna, M.D., Bengtsson, J.E., Craig, D. \& Dröes, R.-. 2009, "A user driven approach to develop a cognitive prosthetic to address the unmet needs of people with mild dementia", Pervasive and Mobile Computing, vol. 5, no. 3, pp. 253-267.

Demiris, G., Oliver, D.P., Dickey, G., Skubic, M. \& Rantz, M. 2008, "Findings from a participatory evaluation of a smart home application for older adults", Technology \& Health Care, vol. 16, no. 2, pp. 111-118.

Diamantopoulos, A., \& Siguaw, J.A. (2000). Introducing LISREL. Thousand Oaks, CA: Sage Publications.

Dickinson, A. \& Gregor, P. 2006, "Computer use has no demonstrated impact on the well-being of older adults", International Journal of Human Computer Studies, vol. 64, no. 8, pp. 744-753.

Fisher, R.J., \& Price, L.L. (1992). An Investigation into the Social Context of Early Adoption Behavior. Journal of Marketing Research, 19(3), 477-486.

Fornell, C., \& Larcker, D.F. (1981). Evaluating Structural Equation Models with Unobservable Variables and Measurement Error. Journal of Marketing Research, 18(1), 39-50.

Fänge, A. \& Ivanoff, S.D. 2009, "The home is the hub of health in very old age: Findings from the ENABLE-AGE Project", Archives of Gerontology and Geriatrics, vol. 48, no. 3, pp. 340345.

Gefen, D., Karahanna, E., \& Straub, D.W. (2003a). Trust and TAM in Online Shopping: An Integrated Model. MIS Quarterly, 27(1), 51-90. 
Gefen, D., Karahanna, E., \& Straub, D.W. (2003b). Inexperience and Experience with Online Stores: The Importance of TAM and Trust. IEEE Transactions on Engineering Management, 50(3), 307-321.

Glass, C.R., \& Knight, L.A. (1988). Cognitive Factors in Computer Anxiety. Cognitive Therapy and Research, 12(4), 351-366.

Heart, T. \& Kalderon, E. "Older adults: Are they ready to adopt health-related ICT?", International journal of medical informatics, vol. In Press, Corrected Proof.

Hong, S.-J., Thong, J.Y.L., \& Tam, K.Y. (2006). Understanding Continued Information Technology Usage Behavior: A Comparison of Three Models in the Context of Mobile Internet. Decision Support Systems, 42, 1819-1834.

Jelicic, M., \& Kempen, G.I.J.M. (1999). Effect of Self-Rated Health on Cognitive Performance in Community Dwelling Elderly. Educational Gerontology, 25, 13-17.

Jenni Niemelä-Nyrhinen 2007, "Baby boom consumers and technology: shooting down stereotypes", Journal of Consumer Marketing, vol. 24, no. 5, pp. 305-312.

Kinzie, M.B., Delcourt, M.A., \& Powers, S.M. (1994). Computer Technologies: Attitudes and Self-Efficacy Across Undergraduate Disciplines. Research in Higher Education, 35(6), 745-768.

Kondo, N., Kazama, M., Suzuki, K. \& Yamagata, Z. 2008, "Impact of mental health on daily living activities of Japanese elderly", Preventive medicine, vol. 46, no. 5, pp. 457-462.

Lee, B., Chen, Y. \& Hewitt, L. 2011, "Age differences in constraints encountered by seniors in their use of computers and the internet", Computers in Human Behavior, vol. 27, no. 3, pp. 12311237.

Lee, E.-J., Lee, J., \& Eastwood, D. (2003). A Two-Step Estimation of Consumer Adoption of Technology-Based Service Innovations. Journal of Consumer Affairs, 37(2), 256.

LeRouge, C., Ma, J., Sneha, S. \& Tolle, K. "User profiles and personas in the design and development of consumer health technologies", International journal of medical informatics, vol. In Press, Corrected Proof.

Long, J.S. (1983). Covariance Structure. Beverly Hills, CA: Sage Publications.

Loyd, B.H., \& Gressard, C. (1984). Reliability and Factorial Validity of Computer Attitude Scales. Educational and Psychological Measurement, 44, 501-505.

Loyd, B.H., \& Loyd, D.E. (1985). The Reliability and Validity of an Instrument for the Assessment of Computer Attitudes. Educational and Psychological Measurement, 45, 903-908. 
Lunsford, D.A., \& Burnett, M.S. (1992). Marketing Product Innovations to the Elderly: Understanding the Barriers to Adoption. Journal of Consumer Marketing, 9(4), 53-63.

Matthews, J., Beach, S., Downs, J., Bruine de Bruin, W., Mecca, L. \& Schulz, R. 2010, " Preferences and concerns for quality of life technology among older adults and persons with disabilities: National survey results", Technology and Disability, vol. 22, no. 1-2, pp. 5-15.

Mitzner, T.L., Boron, J.B., Fausset, C.B., Adams, A.E., Charness, N., Czaja, S.J., Dijkstra, K., Fisk, A.D., Rogers, W.A. \& Sharit, J. 2010, "Older adults talk technology: Technology usage and attitudes", Computers in Human Behavior, vol. 26, no. 6, pp. 1710-1721.

Meuter, M.L., Ostrom, A.L., Bitner, M.J., \& Roundtree, R. (2003). The Influence of Technology Anxiety on Consumers Use and Experiences with Self-Service Technologies. Journal of Business Research, 56(11), 899-906.

Monk, A., Hone, K., Lines, L., Dowdall, A., Baxter, G., Blythe, M. \& Wright, P. 2006, "Towards a practical framework for managing the risks of selecting technology to support independent living", Applied Ergonomics, vol. 37, no. 5, pp. 599-606.

Moschis, G.P. (1992). Gerontographics: A Scientific Approach to Analyzing and Targeting the Mature Market. The Journal of Services Marketing, 6(3), 17-26.

Normann, R. \& Ramírez, R. 1993, "From value chain to value constellation: Designing interactive strategy", Harvard business review, vol. 71, no. 4, pp. 65-77.

Nugent, C.D., Finlay, D.D., Fiorini, P., Tsumaki, Y. \& Prassler, E. 2008, "Home automation as a means of independent living", IEEE Transactions on Automation Science and Engineering, vol. 5, no. 1, pp. 1-8.

Olsson, U. (1979). Maximum Likelihood Estimation of the Polychoric Correlation Coefficient. Psychometrika, 44(4), 443-460.

Oyedele, A., \& Simpson, P.M. (2007). An Empirical Investigation of Consumer Control Factors on Intention to Use Selected Self-Service Technologies. International Journal of Service Industry Management, 18(3), 287-306.

Pak, C., \& Kambil, A. (2006). Over 50 and Ready to Shop: Serving the Aging Consumer. Journal of Business Strategy, 27(6), 18-28.

Passik, S.D., Lundberg, J.C., Rosenfeld, B., Kirsh, K.L., Donaghy, K., Theobald, D., Lundberg, E., \& Dugan, W. (2000). Factor Analysis of the Zung Self-Rating Depression Scale in a Large Ambulatory Oncology Sample. Psychosomatics, 41(2), 121-127. 
Peine, A. 2009, "Understanding the dynamics of technological configurations: A conceptual framework and the case of Smart Homes", Technological Forecasting and Social Change, vol. 76, no. 3, pp. 396-409.

Potosky, D., \& Bobko, P. (1998). The Computer Understanding and Experience Scale: A SelfReport Measure of Computer Experience. Computers in Human Behavior, 14(2), 337-348.

Rigdon, E.E. (1998). Structural Equation Modeling. In G.A. Marcoulides (Ed.), Modern Methods for Business Research (pp. 251-294). Mahwah: Lawrence Erlbaum Associates.

Salovaara, A., Lehmuskallio, A., Hedman, L., Valkonen, P. \& Näsänen, J. 2010, "Information technologies and transitions in the lives of 55-65-year-olds: The case of colliding life interests", International Journal of Human-Computer Studies, vol. 68, no. 11, pp. 803-821.

Selwyn, N. (1997). Student's Attitudes toward Computers: Validation of a Computer Attitude Scale for 16-19 Education. Computers \& Education, 28(1), 35-41.

Shaft, T.M., Sharfman, M.P., \& Wu, W.W. (2004). Reliability Assessment of the Attitude towards Computers Instrument (ATCI). Computers in Human Behavior, 20, 661-689.

Steenkamp, J.-B.E.M., \& Baumgartner, H. (1998). Assessing Measurement Invariance in CrossNational Consumer Research. Journal of Consumer Research, 25(1), 78-90.

Szmigin, I., \& Carrigan, M. (2000). Older Consumer as Innovator: Does Cognitive Age Hold the Key? Journal of Marketing Management, 16, 505-527.

Vaez, M., Kristenson, M., \& Laflamme, L. (2004). Perceived Quality of Life and Self-Rated Health among First-Year University of Students. Social Indicators Research, 68(2), 221-234.

van Hoof, J., Kort, H.S.M., Duijnstee, M.S.H., Rutten, P.G.S. \& Hensen, J.L.M. 2010, "The indoor environment and the integrated design of homes for older people with dementia", Building and Environment, vol. 45, no. 5, pp. 1244-1261.

Venkatesh, V., Speier, C., \& Morris, M.G. (2002). User Acceptance Enablers in Individual Decision Making About Technology: Toward an Integrated Model. Decision Sciences, 33(2), 297-316.

Verbrugge, L.M., \& Yang, L.-s. (2002). Aging with Disability and Disability with Aging. Journal of Disability Policy Studies, 12(4), 253-267.

Wherton, J.P. \& Monk, A.F. 2008, "Technological opportunities for supporting people with dementia who are living at home", International Journal of Human-Computer Studies, vol. 66, no. 8, pp. 571-586. 
Vijayasarathy, L.R. (2004). Predicting Consumer Intentions to Use On-Line Shopping: The Case for an Augmented Technology Acceptance Model. Information \& Management, 41, 757-762.

Vuori, S., \& Holmlund-Rytkönen, M. (2005). 55+ People as Internet Users. Marketing Intelligence \& Planning, 23(1), 58-76. 